\title{
PCR-Based Detection of Parental Origin of Extra Chromosome 21 in Down Syndrome
}

\author{
S.K. Dey and Sujoy Ghosh \\ Molecular Cytogenetics Laboratory, Department of Zoology, Presidency College, 86/1 College \\ Street, Kolkata 700 073, West Bengal, India
}

KEYWORDS Down syndrome; trisomy 21; parental origin; PCR; microsatellite markers

\begin{abstract}
Down syndrome (DS) is one of the most frequent chromosomal abnormalities in humans and is associated with mental retardation.It is usually caused by the presence of an extra chromosome 21.The parental origin of the extra chromosome has been studied in twenty families each with a clinically suspected trisomy 21 proband.The trisomy 21 was confirmed by both chromosomal and molecular analyses.Molecular analysis was carried out by PCR based method, using polymorphic microsatellite markers D21S11 and D21S2055 situated on the long arm of the chromosome 21 at $21 \mathrm{q} 21$ and 21q22 respectively. The amplified products were subjected to polyacrylamide gel electrophoresis and alleles were scored by staining with ethidium bromide. Trisomy 21 Down syndrome was detected by the presence of three distinct alleles and transmission of alleles from parents to the offspring was determined in all but six families .Parental origin was found to be maternal in nine families and paternal in five families .The mean maternal and paternal age of our subjects were $29 \pm 6.9$ and $35 \pm 6.9$ years respectively. Our results further demonstrate the usefulness of highly polymorphic microsatellite markers for the accurate determination of parental origin of the extra chromosome 21 in Down syndrome and also emphasize the fact that the trisomy 21 was due to meiotic errors in maternal chromosomes.
\end{abstract}

\section{INTRODUCTION}

The estimated frequency of Down syndrome or trisomy 21 was one in 700 live births (Mueller and Young 1995). The syndrome is associated with mental retardation, delayed developmental milestones and characteristic physical features. The parental origin of the extra chromosome 21 has so far been studied by conventional methods of identifying morphological variations in chromosome 21 in given families. However, this method was found to be less informative and accurate determination of parental origin was not possible using this conventional method (Carothers 1987; Peterson et al. 1991).On the other hand, the introduction of analytic techniques involving highly polymorphic microsatellite markers and polymerase chain reaction (PCR) has facilitated the accurate determination of parental origin of the extra chromosome 21 (Antonarakis 1991; Peterson et al.1991; Pangolas et al. 1992). The chief advantages of using DNA polymorphic markers are that they are highly informative and are spreaded throughout the length of the long arm of the chromosome 21 . As a result, the parental origin can be determined by choosing appropriate markers either from the centromeric region or from Down syndrome critical region (DSCR) or from telomeric region
(Antonarakis 1998). Additionally, considering the poor hybridization efficiency of fluorescent in situ hybridization technique (FISH), PCR based method was reported to be an alternative or complementary method to FISH in the study of parental origin (Samura et al. 2001).

The aim of the present study was to evaluate the simple PCR based DNA diagnostic method (Ghosh and Dey 2003) for the determination of the parental origin of the extra chromosome 21 in trisomy 21 Down syndrome, as the knowledge of the parental origin is prerequisite for investigations of genetic and environmental factors that may affect the meiotic process.

\section{MATERIALSAND METHODS}

Families: A total of twenty families each with a child with chromosomally diagnosed trisomy 21 were studied .In each family effort has been made to study the parents, probands, siblings and close relatives depending on the availability of the subjects. The maternal and paternal age at the time of birth of trisomic proband have been recorded .Families with more than one offspring with trisomy 21 were not included in the present study. Only proband was available for investigation in DS1 while in DS11, DS17 and DS20 one of the parent was available. In DS 17, 
a close relative (mother's sister, aunt) was also studied along with the proband.

Methods: Heparinized blood samples of the subjects were received from the Paediatric units of different Medical Colleges of Kolkata for karyotyping and diagnosis. Lymphocyte culture was set up by following the method of Gosden et al. (1992) and chromosomal preparation was made by following the conventional air drying method. For molecular analysis, genomic DNA was isolated from uncoagulated blood samples of trisomic proband and parents by using salting out procedure of Miller et al. (1988). DNA polymorphism was studied by using two tetranucleotide markers D21S11 and D21S2055 situated on chromosome $\mathbf{2 1}$ at $\mathbf{2 1 q} 21$ and $\mathbf{2 1 q 2 2}$ respectively. The sequence and PCR conditions for the primers were as follows:

\section{D21S11:}

F-5'GTGAGTCAATTCCCCAAG $3^{\mathrm{I}}$ R-5'GTTGTATTAGTCAATGTTCTCC $3^{1}$ D21S2055:

F-5 ${ }^{\mathrm{I}}$ AACAGAAACCAATAGGCTATCTTATC $3^{\mathrm{I}}$ R-5'TACAGTAAATCACTTGGTAGGAGA $3^{\text {I }}$

For the first primer, after initial denaturaton at $95^{\circ} \mathrm{C}$ for 5 min., 30 cycles of PCR amplification were done at $95^{\circ} \mathrm{C}$ for $30 \mathrm{~s} ; 60^{\circ} \mathrm{C}$ for $30 \mathrm{~s} ; 72^{\circ} \mathrm{C}$ for $30 \mathrm{~s}$ and final extension for $9 \mathrm{~min}$ at $72^{\circ} \mathrm{C}$. For the second primer, after initial denaturation at $94^{\circ} \mathrm{C}$ for $3 \mathrm{~min}, 30$ cycles of PCR amplification were done at $95^{\circ} \mathrm{C}$ for $30 \mathrm{~s} ; 36^{\circ} \mathrm{C}$ for $30 \mathrm{~s} ; 72^{\circ} \mathrm{C}$ for $1 \mathrm{~min}$ and final extension for $3 \mathrm{~min}$ at $72^{\circ} \mathrm{C}$. PCR (polymerase chain reaction) reactions were carried out in a Perkin-Elmer Gene Amp.2400 Thermal Cycler. PCR products were analysed by following the method described earlier by Ghosh and Dey (2003). Trisomy 21 patients revealed three distinct alleles and the parental origin of extra chromosome 21 was determined after comparing the bands of father, mother and proband.

\section{RESULTS}

Cytogenetic Studies: Analysis of chromosome and karyotype revealed a diploid count of $2 n=47,+21$ in probands of all twenty families. All the parents of the proband showed normal chromosome count and normal karyotype.

Molecular Studies of Parental Origin: Analysis of DNA polymorphism was performed on all members of the nuclear families containing one proband with trisomy 21 . The parental origin of extra chromosome was assigned after the polymorphic alleles in a given family were scored. The results of the DNA marker study of parental origin were summarized in Table 1(see examples in figures 1-4). Of the twenty families studied, we were able to specify parental origin in all but six

Table 1: Parental origin of the extra chromosome 21 in Down syndrome patients

\begin{tabular}{|c|c|c|c|c|c|c|}
\hline \multirow{2}{*}{$\begin{array}{l}\text { Family } \\
\text { code }\end{array}$} & \multirow{2}{*}{$\begin{array}{l}\text { Primer } \\
\text { code }\end{array}$} & \multicolumn{4}{|c|}{ Genotype } & \multirow{2}{*}{$\begin{array}{r}\text { Parental } \\
\text { origin }\end{array}$} \\
\hline & & $D S$ & $F A$ & $M O$ & & \\
\hline DS1 & $3 F / 3 R$ & $2,5,6$ & - & - & & unsolved \\
\hline DS2 & $3 F / 3 R$ & $5,6,8$ & 5,6 & 2,8 & & paternal \\
\hline DS11 & $3 F / 3 R$ & $1,2,3$ & - & 2,3 & & unsolved \\
\hline DS12 & $1 \mathrm{~F} / 1 \mathrm{R}$ & $1,2,3$ & 1,3 & 2,2 & & paternal \\
\hline DS13 & $1 \mathrm{~F} / 1 \mathrm{R}$ & $4,5,7$ & 5,6 & 4,5 & & maternal \\
\hline DS15 & $3 F / 3 R$ & $1,3,5$ & 1,3 & 2,3 & & unsolved \\
\hline DS16 & $3 \mathrm{~F} / 3 \mathrm{R}$ & $1,3,4$ & 1,3 & 1,4 & & unsolved \\
\hline DS17 & $3 \mathrm{~F} / 3 \mathrm{R}$ & $2,3,5$ & - & 2,5 & $2,5(\mathrm{~A})$ & unsolved \\
\hline DS18 & $1 \mathrm{~F} / 1 \mathrm{R}$ & $3,3,4$ & 3,3 & 2,4 & & paternal \\
\hline DS19 & $1 \mathrm{~F} / 1 \mathrm{R}$ & $2,6,7$ & 2,4 & 6,7 & & maternal \\
\hline DS20 & $1 \mathrm{~F} / 1 \mathrm{R}$ & $1,3,5$ & 1,8 & - & & unsolved \\
\hline DS21 & $1 \mathrm{~F} / 1 \mathrm{R}$ & $1,3,4$ & 1,3 & 2,4 & & paternal \\
\hline $\mathrm{DS} 22$ & $1 \mathrm{~F} / 1 \mathrm{R}$ & $1,4,5$ & 1,3 & 4,5 & & maternal \\
\hline DS23 & $1 \mathrm{~F} / 1 \mathrm{R}$ & $1,3,4$ & 7,4 & 1,3 & & maternal \\
\hline DS24 & $1 \mathrm{~F} / 1 \mathrm{R}$ & $1,2,3$ & 1,6 & 2,3 & & maternal \\
\hline DS26 & $3 \mathrm{~F} / 3 \mathrm{R}$ & $4,5,7$ & 4,7 & 1,5 & & paternal \\
\hline DS27 & $3 \mathrm{~F} / 3 \mathrm{R}$ & $1,3,4$ & 4,8 & 1,3 & & maternal \\
\hline DS28 & $3 \mathrm{~F} / 3 \mathrm{R}$ & $7,8,2$ & 5,8 & 2,7 & & maternal \\
\hline DS31 & $3 \mathrm{~F} / 3 \mathrm{R}$ & $2,3,7$ & 3,3 & 2,7 & & maternal \\
\hline DS32 & $3 F / 3 R$ & $3,6,8$ & 1,3 & 6.8 & & maternal \\
\hline
\end{tabular}

DS-Down syndrome, FA-Father, MO-Mother, A-Aunt, 3F/3R-D21S2055, 1F/1R-D21S11 
families. In DS1, only proband was available for study while in DS11, DS17 and DS20 either father or mother was available for investigation (Table 1). In case of DS17, mother and maternal sister(aunt) revealed identical genotypes while in DS16 parental origin remain unsolved. In DS 15 , the origin of the allele 5 of the proband remain unsolved and it seems that primers were not informative in DS15 and DS16. Nevertheless, parental origin was found to be maternal in nine families and paternal in five families. The mean maternal age was $29 \pm 6.9$ and paternal age was $35 \pm 6.9$. All the alleles were scored visually and were within the size range of 100-226 base pairs.

\section{DS denotes the Down syndrome offspring with trisomy 21, Fa Father, Mo Mother and Au Aunt.}
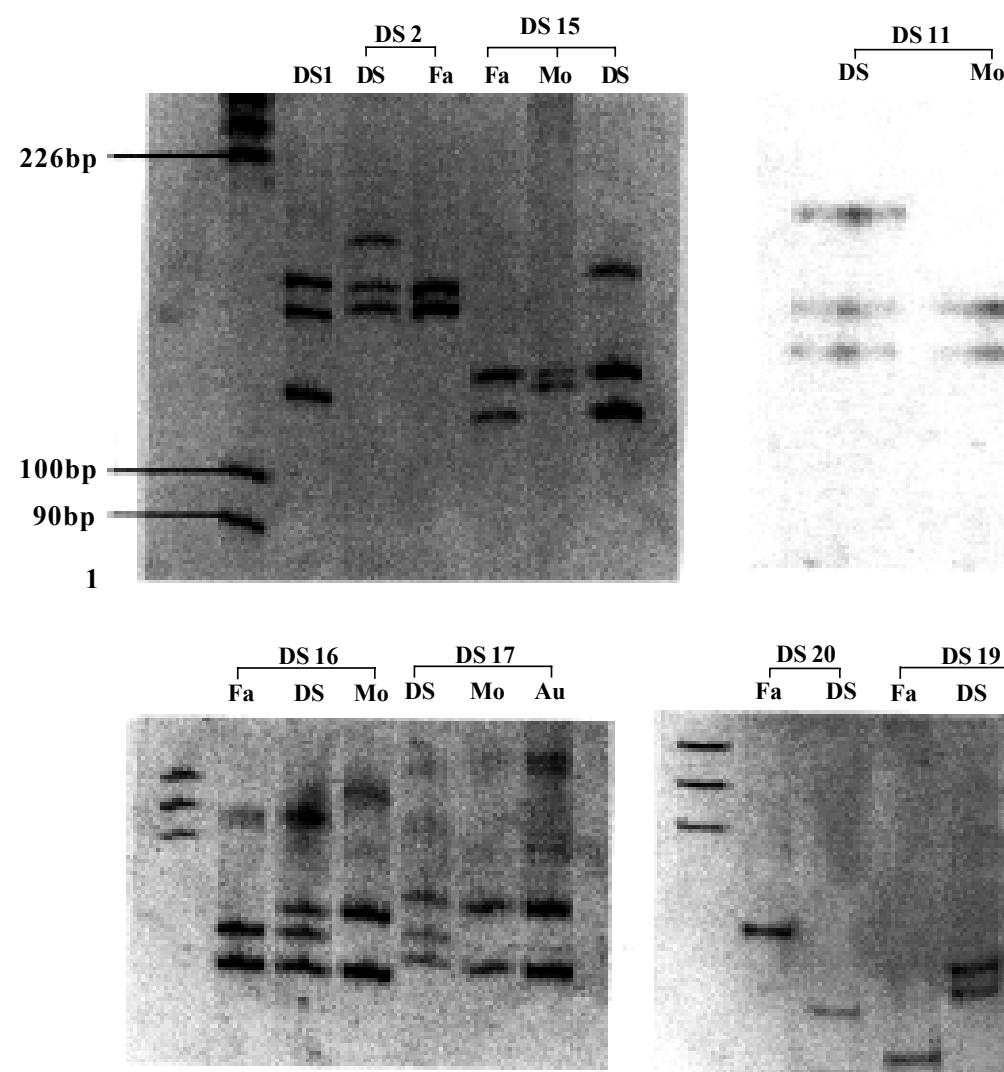

3

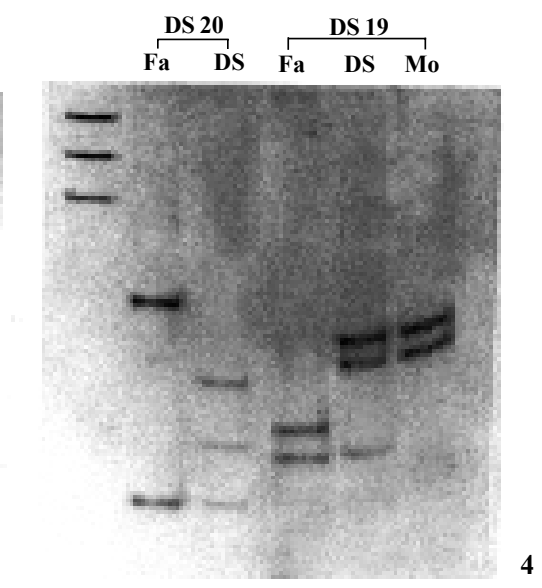

Fig. 1. The first lane contains a size marker pBR322/Alu1 digestion.In the following lane trisomic proband DS1 shows three alleles 2,5 and 6 . DS2 has three alleles 5,6 and 8 of which 5 and 6 originates with father.DS15 shows father, mother and trisomic proband with alleles 1,3 and 2,3 and $1,3,5$ respectively (allele 1 is the shortest and allele 6 the longest in this case).

Fig. 2. DS11 shows three distinct alleles 1,2 and 3 of which 2 and 3 originates with mother.

Fig. 3. Showing DS16 and DS17.In DS16, father has alleles 1 and 3,mother has alleles 1 and 4 and trisomic proband has three alleles 1,3 \& 4 . DS 17 shows trisomic proband,mother and aunt with alleles $2,3,5$ and 2,5 and 2,5 respectively of which 2,5 originates with mother.

Fig. 4. Showing DS20 and DS19.In DS20 father has alleles 1 and 8 , and trisomic proband has alleles 1,3 and 5. In DS19, the father has alleles 2 and 4, trisomic proband shows three alleles 2,6 and 7 of which alleles 6 and 7 originates with mother. 


\section{DISCUSSION}

The determination of the parental origin of the extra chromosome 21 in trisomy 21 Down syndrome is of importance for the understanding of the mechanism of nondisjunction and also for the elucidation of the maternal age effect. The analysis described here using the microsatellite markers D21S11 and D21S2055 showed that the origin of extra chromosome was maternal in about $45 \%$ of the cases of free trisomy 21 and paternal in about $25 \%$. These results contrast with those obtained in earlier molecular studies where paternal nondisjunction accounts for approximately $5 \%-6 \%$ of trisomy 21 cases only (Antonarakis 1991; Sherman 1991; Ko et al.1998).Furthermore, the mean maternal age for 20 Down syndrome families was $29 \pm 6.9$ years, not significantly different from the value of $30 \pm 5.2$ years reported by Sherman (1991). However, there are several possible explanations for the discrepancy in the proportion of paternally derived cases. First, it might be said that the population sample for the DNA analysis was different since we have studied the Indian population sample while data on European and Chinese population samples were available for comparison. Second, the discrepancy may simply reflect the fact that we have studied a relatively small number of Down syndrome families with DNA markers and that as more data accumulate the accurate proportion of paternally derived cases could be obtained. It is, however, interesting to note that the paternal contribution to the origin of nondisjunction in trisomy 21 in our study was as high as $25 \%$. The persons with paternally derived trisomy 21 were not apparently different in clinical presentation from those with maternally derived trisomy 21 . On the other hand, mean paternal age in our study was $35 \pm 6.9$ which was higher than mean paternal age of $31 \pm 4.5$ and $31 \pm 5.5$ reported by Sherman (1991) and Antonarakis (1991) respectively. Paternal origin of trisomy 21 was reported earlier by Blanco et al.(1998) while Ballesta et al.(1998) did not find any significant difference between maternal and paternal origin of extra chromosome in trisomy 21. However,our results were consistent with the earlier findings that maternal nondisjunction played a significant role in the pathogenesis of trisomy 21 .

\section{ACKNOWLEDGEMENT}

SKD is thankful to University Grants Commission, New Delhi, for financial assistance.

\section{REFERENCES}

Antonarakis SE 1991. Parental origin of the extra chromosome in trisomy 21 as indicated by analysis of DNA polymorphism. $N$ Engl J Med, 324: 8726.

Antonarakis SE 1998. 10 years of genomics, chromosome 21 and Down syndrome. Genomics, 51: 1-16.

Ballesta F, Queralt R, Gomez D, Solsona E 1999. Parental origin and meiotic nondisjunction in 139 cases of trisomy 21. Ann Genet, 42(1): 11-5.

Blanco J, Gabau E, Gomez D, Baena N, Guitart M, Egozcue J, Vidal F 1998. Chromosome 21 in a population with a high prevalence of Down syndrome :increased incidence in cases of paternal origin. Am J Hum Genet, 63(1): 10676-72.

Carothers AD 1987. Down syndrome and maternal age :the effect of erroneous assignment of parental origin. Am J Hum Genet, 40:147-150.

Gosden CM, Davidson C, Robertson M 1992. Lymphocyte culture. In: DE Rooney and BH Czepulkowski (Eds): Human Cytogenetics. A Practical Approach Vol.1. Constitutional Analysis. $2^{\text {nd }}$ Ed. NY: Oxford Univ. Press. pp.32-54.

Ghosh S, Dey SK 2003. DNA diagnosis of Down syndrome using polymerase chain reaction and polymorphic microsatellite markers. Int $J$ Hum Genet, 3(1): 17-20.

Ko TM, Hwa HI, Tseng LH, Lin YW, Cheung YP. 1998. Fluorescence microsatellite analysis to study the parental origin of the supernumerary chromosome in Down's syndrome. Int J Gynaecol Obstet, 61(2): 149-53.

Miller SA, Dykes DD , Polesky HF 1988. A simple salting out procedure for extracting DNA from human nuclear cells. Nucleic Acids Res, 16:1215.

Muller RF, Young ID 1995. Chromosome disorders In: Emery's Elements of Medical Genetics. UK: Churchill-Livingstone. pp.215-227.

Peterson MB, Schinzel AA, Blinkert F, Tranebjaerg L 1991. Use of short sequence repeat DNA polymorphism after PCR amplification to detect the parental origin of the additional chromosome 21 in Down syndrome. Am J Hum Genet, 48(1): 65-71.

Pangolas CG, Talbot CC, Lewis JG, Adelsberger PA, Peterson MB 1992. DNA polymorphism analysis in families with recurrence of free trisomy 21. Am J Hum Genet, 51(5): 1015-27.

Samura O, Sohda S, Johnson KL, Pertl B, Ralston S, Delli-Bovi LC 2001. Diagnosis of trisomy 21 in fetal nucleated erythrocytes from maternal blood by use of short tandem repeat sequences. Clin Chem, 47(9): $1622-6$.

Sherman SL 1991. Trisomy 21: Association between Reduced recombination and nondisjunction. $\mathrm{Am} \mathrm{J}$ Hum Genet, 49: 608-620. 